\title{
NUTRITIONAL IMPLICATIONS FOR NITROGEN AND MINERAL BUDGETS FROM ANALYSIS OF GUANO OF THE BIG BROWN BAT EPTESICUS FUSCUS (CHIROPTERA: VESPERTILIONIDAE)
}

\author{
Eugene H. Studier, Dennis P. Viele* and Steven H. Sevick \\ Department of Biology, University of Michigan-Flint, Flint, MI 48502-2186, U.S.A. \\ Telephone: (313) 762-3360
}

(Received 27 February 1991)

\begin{abstract}
Analysis of nitrogen, sodium, calcium, magnesium, iron, and potassium levels in big brown bat guano throughout much of the summer roosting period was performed.

2. Based on the tenet that low, non-variable levels of an element in feces indicate dietary inadequacy for that element, female big brown bats are routinely and severely stressed for calcium and may become stressed for iron by the end of the summer. Similar elemental stresses, although not as severe, exist for males.
\end{abstract}

\section{INTRODUCTION}

Studies of nutritional budgets in animals focus characteristically on energy or caloric (carbon) economies. Studies on bats are typical (McNab, 1982). Water economies are less studied (Bassett and Studier, 1988). This emphasis on energy budgets suggests that if an animal meets its caloric demands, all other nutritional requirements will be satisfied. Except for the very unlikely ingestion of perfect food which contains adequate quantities of all other elements, vitamins, etc., ingestion of minimal calories (fixed carbon) to meet energy budgets would rarely, if ever, provide adequate intake of all other nutrients. Free-living, normally nourished, female little brown bats, Myotis lucifugus, for example, are severely calcium stressed throughout much of their summeractive period (Kwiecinski et al., 1987a).

Energy budgets in bats have been established by a variety of techniques (Kunz and Nagy, 1988), including estimates based on fecal production (Ransome, 1973). Rate of fecal production reflects rate of biomass ingested and, similarly, fecal composition should reflect composition of ingested biomass. Minimal or inadequate ingested level for a given element should initiate physiological mechanisms which maximize assimilation of that element and, therefore, minimize fecal concentration of that element.

We report here the fecal concentrations of sodium, potassium, calcium, iron, magnesium and nitrogen for male big brown bats, Eptesicus fuscus, throughout an entire summer roosting period and for females beginning in mid-lactation through the end of their summer roosting period. Nutritional implications generated by the level and pattern of elements in fecal samples are also reported.

*Present address: Department of Biology, Eastern Michigan University, Ypsilanti, MI 48197, U.S.A.

\section{MATERIALS AND METHODS}

Big brown bats were studied in two roosts during the summer of 1989. Fecal collections were begun on 13 April (designated day 0 for purposes of analysis) in the first roost which was a large attic in a building in Grand Blanc, Genesee Co., MI, U.S.A. Prior to 1989 , this roost had housed a large ( $>100$ individuals) maternity colony of big brown bats for at least the previous 15 summers. Building construction in late 1988 apparently displaced the females. Throughout the summer of 1989 , the roost was occupied by only two males and is hereafter known as the male roost. Fecal collections were begun in the second roost, a small barn located in rural Livingston Co., MI, on 5 July 1989. This roost harbored about 20 adult females and their young and is identified as the maternity colony.

Guano collectors, cafeteria trays covered with white paper towels, were positioned wherever guano had accumulated in previous years. Collectors were checked weekly and, when present, all accumulated guano not in contact with urine stains was collected and towelling replaced as needed. Collections were continued until the roosts were abandoned (30 September for the male roost and 15 October for the maternity roost). Guano was returned to the lab and dried to constant weight at $50-60^{\circ} \mathrm{C}$.

Samples $(50-80 \mathrm{mg})$ of typical dried guano (4-8 pellets) from total weekly accumulations were digested and, after appropriate dilution, were analysed for nitrogen, sodium, calcium, iron $\left(\mathrm{Fe}^{2+}\right.$ and $\mathrm{Fe}^{3+}$ combined), magnesium and potassium levels (Studier et al., 1988). Essentially all guano from the male roost was analysed (1-6 samples/week). Six samples of weekly typical guano from the female roost were analyzed except for the sampling period of 12-19 July when 14 samples were analysed. Atypical guano found in the maternity roost from 5-19 July (very large, grey pellets) and from 24 September through 15 October (small, black pellets) were digested and analysed separately.

Data analyses and figure preparation were done using SYSTAT and SYGRAPH (Wilkinson 1987, 1989).

\section{RESULTS AND DISCUSSION}

For males, linear regression analyses indicate a significant decrease in fecal level of each element tested, except sodium, over the summer. Similar 
Table 1. Linear regression summary of fecal element concentration over time (day) in big

\begin{tabular}{lccccc}
\hline \multicolumn{5}{c}{ brown bats } \\
\hline $\mathrm{DV}$ & $\mathrm{S}$ & Slope & Intercept & $\mathrm{F}$ & $r^{2}$ \\
\hline $\mathrm{N}$ & $\mathrm{M}$ & $-0.020 \pm 0.006$ & $19.49 \pm 0.52$ & 11.342 & 0.130 \\
$\mathrm{~K}$ & $\mathrm{M}$ & $-0.090 \pm 0.017$ & $18.21 \pm 1.50$ & 27.926 & 0.269 \\
$\mathrm{Ca}$ & $\mathrm{M}$ & $-0.015 \pm 0.004$ & $4.550 \pm 0.337$ & 14.997 & 0.165 \\
$\mathrm{Mg}$ & $\mathrm{M}$ & $-0.023 \pm 0.005$ & $5.915 \pm 0.429$ & 21.719 & 0.222 \\
$\mathrm{Fe}$ & $\mathrm{M}$ & $-0.014 \pm 0.003$ & $2.333 \pm 0.253$ & 23.970 & 0.240 \\
$\mathrm{Ca}$ & $\mathrm{F}$ & $0.013 \pm 0.003$ & $-0.791 \pm 0.327$ & 25.559 & 0.242 \\
\hline
\end{tabular}

In all cases $P<0.001 ; D V=$ dependent variable; units for minerals $=$ ppt dry weight and for $N=\%$ dry weight; $\mathrm{S}=\operatorname{sex}(\mathrm{M}=$ male, $\mathrm{F}=$ fermale); $\mathrm{df}$ for $\mathrm{M}=1$ and 76 and for $\mathrm{F}=1$ and 80. Values for slope and intercept are coefficients $\pm \mathrm{SE}$

analyses of maternity roost guano show no relationships with time except for calcium, which increases over time (Table 1). Inspection of the raw data, e.g. for calcium (Fig. 1) and for iron (Fig. 2), however, illustrates that trends found by the analyses above are, in males, largely the result of decreased data variability over time. For fecal calcium levels in females (Fig. 1), the increase over time, found statistically, is unduly influenced by several very high values found at the end of the period of observation. These changes in variability are reflected by the standard error patterns for measured elements as summarized in Table 2.

The extreme variability in fecal element levels found for males in April may reflect differences in physiological status (especially digestive efficiency or thermoregulatory capacity) of these bats that have recently emerged from hibernation, may reflect highly variable composition of insects available as opportunistic prey items, or may reflect a lack of selective feeding by the bats. The progressive decrease in variability of fecal element levels in males throughout the summer may then be explained by increasing consistency in physiological status, more consistent

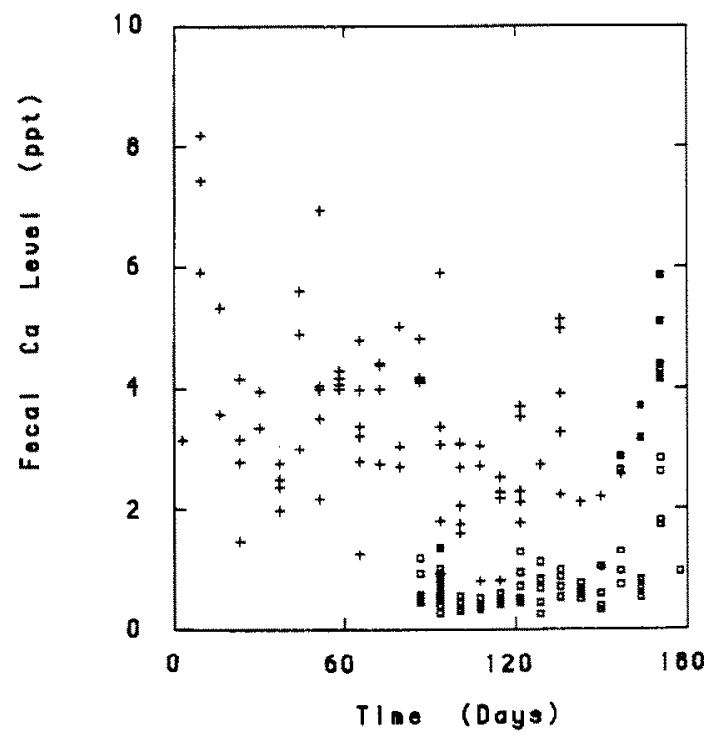

Fig. 1. Calcium level (ppt) in dry big brown bat guano throughout the summer of 1989 (guano from males $=+$ and females $=\square$ ). Atypical guano from female $E$. fuscus are shown by symbols which are partially shaded (=large, grey pellets) or completely shaded (=small, black pellets). Day $0=13$ April 1989; Day $180=14$ October 1989; and, Day 100 is the approximate end of lactation. Calcium requirement for growth and reproduction in small mammals is 4.0-8.0 ppt (National Research Council, 1978). composition of prey taken opportunistically, or more selective feeding from a wider variety of available prey insects. Reduced variability in all fecal elemental concentrations throughout the summer in male Eptesicus fuscus may also imply nutritional inadequacy for some elements, especially iron.

Minimal requirements for growth and reproduction for the clements measured have been reported for only laboratory rats and mice, gerbils, guinea pigs and hamsters (National Research Council, 1978). Although laboratory mice are the only species studied with body masses near those of big brown bats, elemental requirements in these rodents appear to be independent of size and will be used as estimates representative of small mammals.

Minimal dietary nitrogen requirement, as ideal protein, for growth and reproduction in small mammals ranges from 1.9 to $2.9 \%$ of food dry weight (National Research Council, 1978). Guano from both sexes contain similar nitrogen levels (Table 2) which are at least 5 times the minimal requirement. Although urinary excretion of nitrogen contributes significantly to nitrogen budgets and some of the dietary nitrogen is present in refractory, aminated polysaccharides in the exoskeleton of insects, fecal data indicate no dietary deficiency for nitrogen. Relatively constant fecal nitrogen levels during the 80-105

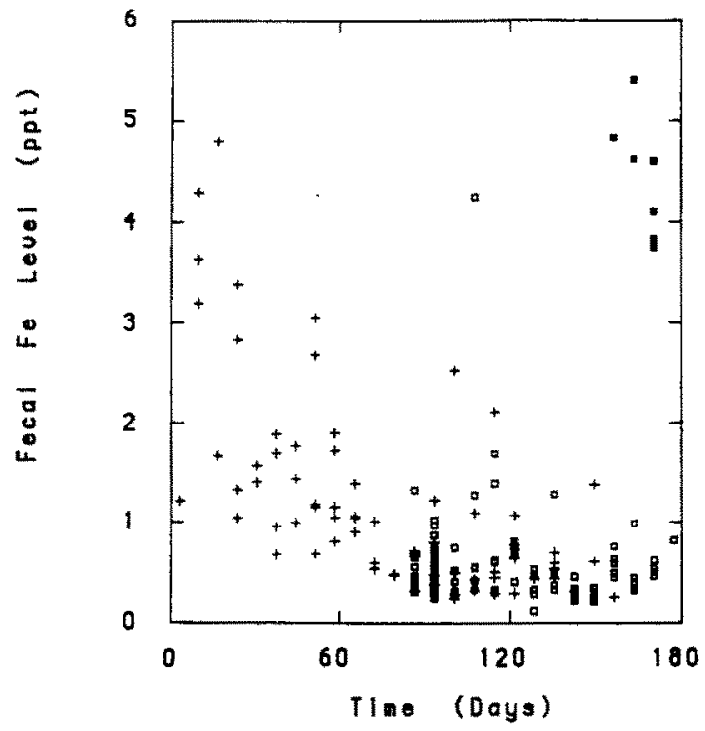

Fig. 2. Iron level (ppt) in dry big brown bat guano throughout the summer of 1989. See legend of Fig. 1 for further explanation. Iron requirement for growth and reproduction in small mammals is $0.025-0.140 \mathrm{ppt}$ (National Research Council, 1978). 
Table 2. Fecal levels of $\mathrm{N}$ (\% dry weight) and $\mathrm{Na}, \mathrm{K}, \mathrm{Ca}, \mathrm{Mg}$, and $\mathrm{Fe}$ (ppt dry weight) in typical guano of male (M) and female (F) big brown bats, Eptesicus fuscus, during the summer of 1989

\begin{tabular}{|c|c|c|c|c|c|c|}
\hline $\begin{array}{l}\text { Days } \\
N(\mathrm{M}) \\
N(\mathrm{~F})\end{array}$ & $\begin{array}{c}0-40 \\
16 \\
-\end{array}$ & $\begin{array}{c}40-80 \\
26 \\
-\end{array}$ & $\begin{array}{c}80-125 \\
14 \\
24\end{array}$ & $\begin{array}{c}125-130 \\
13 \\
24\end{array}$ & $\begin{array}{c}130-155 \\
9 \\
16 \\
\end{array}$ & $\begin{array}{c}155-180 \\
18\end{array}$ \\
\hline $\mathrm{M}(\mathrm{N})$ & $20.27 \pm 0.63$ & $17.41 \pm 0.23$ & $16.36 \pm 0.60$ & $17.79 \pm 0.41$ & $17.90 \pm 0.34$ & - \\
\hline $\mathrm{F}(\mathrm{N})$ & - & 工 & $16.70 \pm 0.27$ & $17.05 \pm 0.53$ & $17.29 \pm 0.54$ & $17.84 \pm 0.24$ \\
\hline $\mathrm{M}(\mathrm{Na})$ & $5.987 \pm 0.378$ & $4.724 \pm 0.144$ & $5.989 \pm 0.359$ & $5.943 \pm 0.295$ & $5.516 \pm 0.303$ & - \\
\hline $\mathrm{F}(\mathrm{Na})$ & 二 & 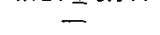 & $7.476 \pm 0.668$ & $8.181 \pm 0.834$ & $9.153 \pm 1.293$ & $10.010 \pm 1.457$ \\
\hline $\mathrm{M}(\mathrm{K})$ & $18.95 \pm 2.85$ & $9.90 \pm 0.52$ & $8.20 \pm 0.51$ & $7.80 \pm 0.52$ & $10.32 \pm 0.69$ & - \\
\hline $\mathbf{F}(\mathbf{K})$ & - & - & $10.24 \pm 0.97$ & $9.00 \pm 0.53$ & $9.95 \pm 0.69$ & $11.24 \pm 0.71$ \\
\hline $\mathrm{M}(\mathrm{Ca})$ & $3.880 \pm 0.464$ & $3.864 \pm 0.219$ & $3.109 \pm 0.363$ & $2.348 \pm 0.234$ & $3.051 \pm 0.438$ & - \\
\hline $\mathrm{F}(\mathrm{Ca})$ & - & 二 & $0.595 \pm 0.040$ & $0.572 \pm 0.051$ & $0.661 \pm 0.053$ & $1.602 \pm 0.279$ \\
\hline $\mathbf{M}(\mathbf{M g})$ & $6.106 \pm 0.584$ & $4.201 \pm 0.338$ & $2.583 \pm 0.155$ & $3.464 \pm 0.212$ & $3.789 \pm 0.247$ & - \\
\hline $\mathrm{F}(\mathbf{M g})$ & - & - & $3.176 \pm 0.156$ & $3.044 \pm 0.151$ & $3.027 \pm 0.179$ & $3.284 \pm 0.088$ \\
\hline $\mathrm{M}(\mathrm{F} \varepsilon)$ & $2.229 \pm 0.310$ & $1.157 \pm 0.123$ & $1.129 \pm 0.447$ & $0.696 \pm 0.133$ & $0.590 \perp 0.102$ & 二 \\
\hline $\mathrm{F}(\mathrm{Fe})$ & - & - & $0.586 \pm 0.049$ & $0.772 \pm 0.165$ & $0.380 \pm 0.062$ & $0.547 \pm 0.040$ \\
\hline
\end{tabular}

$N=$ Number of guano samples analysed in each interval. Day $0=13$ April 1989. Values shown are means \pm SE. Days $80-105$ include the latter half of lactation in females. The first two intervals are 40 days each while the last four are 25 days each

day time span (Table 2), when females are lactating and have high nitrogen need, re-enforces the premise of lack of dietary nitrogen stress.

Growth and reproductive requirement for sodium are $0.5-1.5 \mathrm{ppt}$ of food dry weight in small mammals (National Research Council, 1978). Fecal sodium levels exceed requirements by about 3 times in males and 10 times in females and do not change significantly over time in either sex (Table 2). During periods of overlapping collections, fecal sodium level in females is marginally higher than in males (days $80-105, \quad t=1.96, \quad \mathrm{df}=36, \quad 0.10>P<0.05 ;$ days 105-130, $t=2.53$, df $=35, P<0.02 ;$ and, days $130-155, t=2.74, \mathrm{df}=23, P<0.02$ ) and is markedly more variable than in males (Table 2). Although sodium budgets are also largely influenced by renal function, high and variable fecal sodium levels imply lack of nutritional stress for this mineral, especially in females. Differences in fecal sodium levels between males and females suggest that prey eaten by males may be lower and more consistent in sodium level than insects eaten by females, especially since sodium requirements associated with reproduction would be higher in females. These differences may also relate to different prey availability at the roost locations or different assimilation efficiencies in males and females.

Nutritional requirements in small mammals for potassium are 2.0-7.2 ppt dry food weight (National Research Council, 1978). The statistically significant decrease in fecal potassium levels in males (Table 1) is largely attributable to a few, very high levels of that mineral in guano samples taken in the first few weeks of the post-hibernation period (Table 2). During the period of overlapping collections, average fecal potassium levels in guano from both sexes are similar, exceed dietary need, and exhibit similar variability. As with nitrogen and sodium, renal excretion plays an important role in potassium economy; however, data indicate little probability of dietary potassium inadequacy.

Calcium dietary requirements for growth and reproduction in small mammals are $4.0-8.0$ ppt dry food weight (National Research Council, 1978). Fecal calcium levels from males fall slightly below minimal requirement for this element; however, those levels show considerable variability. These data imply that males consume marginally adequate dietary cal- cium. During the period of overlapping guano collection, fecal calcium levels from females are much lower than levels from males (days 80-105, $t=6.88$, $\mathrm{df}=36, P<0.001$; days $105-130, t=7.41, \mathrm{df}=35$, $P<0.001$; and, days $130-155, t=6.79, \mathrm{df}=23$, $P<0.001)$ and are much less variable in females (Table 2). Additionally, calcium levels in guano from females are nearly an order of magnitude lower than nutritional need. The very low, highly consistent calcium levels found in guano collected from females, coupled with the lack of significant renal contribution to calcium loss, strongly suggest that these bats are in negative calcium balance and are ingesting inadequate amounts of that mineral. Guano collection in the maternity roost started while bats were lactating which represents a period of high calcium need in most mammals. Although lactation ceased on about day 125 , fecal calcium levels remained low and invariant for another 30 days. Fecal calcium level in these bats began to rise only during the last few weeks of summer roost occupancy (Table 2, Fig. 1) which accounts for the apparent positive regression coefficient found (Table 1). Reproductively active, female big brown bats appear to be highly stressed for adequate calcium intake during lactation and most, or all, of the post-lactation (pre-hibernation) period. Histological studies of annual changes in the skeleton, thyroid and parathyroid glands of bats (Kwiecinski et al., 1987a, b) also indicate that females are much more calcium stressed than males. Those studies also indicate that new bone formation in females, i.e. positive calcium balance, is restricted to the immediate post-hibernation period before significant foetal growth rates begin and late post-lactation (pre-hibernation) after females recover from the skeletal demineralization associated with late pregnancy and lactation.

Small mammals require $0.4-1.0 \mathrm{ppt}$ dry food weight of magnesium for growth and reproduction (National Research Council, 1978). The pattern of fecal magnesium level in guano collected from males follows that of other elements, i.e. an apparent negative relation over time which is strongly influenced by high, variable fecal levels during the initial post-hibernation period. Magnesium level in guano from females is higher during the 80-105 day interval $(t=2.69, \mathrm{df}=36, P<0.02)$, not different in the 105-130 day interval and lower in the 130-155 day 
Table 3. Elemental composition of atypical guano collected from female big brown bats. Large, grey (grey) fecal pellets were found while bats were in mid-lactation

\begin{tabular}{lcccccc}
\hline Guano & $N$ & $\begin{array}{c}\mathrm{N} \\
(\%)\end{array}$ & $\begin{array}{c}\mathrm{Na} \\
(\mathrm{ppt})\end{array}$ & $\begin{array}{c}\mathrm{K} \\
(\mathrm{ppt})\end{array}$ & $\begin{array}{c}\mathrm{Ca} \\
\text { (ppt) }\end{array}$ & $\begin{array}{c}\mathrm{Mg} \\
(\mathrm{ppt})\end{array}$ \\
\hline Grey & 12 & $22.15 \pm 0.67$ & $13.270 \pm 0.690$ & $24.10 \pm 0.46$ & $0.732 \pm 0.065$ & $3.243 \pm 0.191$ \\
Black & 7 & $16.64 \pm 0.28$ & $9.672 \pm 0.414$ & $13.31 \pm 0.38$ & $4.184 \pm 0.368$ & $4.440 \pm 0.200$ \\
\hline
\end{tabular}

Small, black (black) pellets were.found in October during the last few weeks of maternity roost occupancy. Units for nitrogen are per cent dry weight $(\%)$ and for all mineral are parts per thousand dry weight (ppt); $N=$ samples analysed; values shown are means \pm SE.

interval ( $t=2.50$, df $=23, P=0.02$ ) than in males (Table 2). All measured fecal magnesium levels, however, are at least 3 times higher than the nutritional requirement. As for calcium, renal excretion of magnesium plays little role in losses of this material. Fecal magnesium level differences between sexes may reflect foraging differences; however, big brown bats appear to ingest adequate dietary quantities of this mineral.

Dietary iron requirements for growth and reproduction in small mammals are $0.025-0.140 \mathrm{ppt}$ food dry weight (National Research Council, 1978). Although fecal levels of iron in both sexes are at least 3 times higher than required levels, iron is poorly assimilated (essentially only as $\mathrm{Fe}^{2+}$ ) by many mammals and is not significantly excreted by the kidneys. Animals may well be expected to assimilate iron less well than average dry mass assimilation which will result in fecal levels which exceed dietary concentrations. The decreasing level of iron in guano from males is associated with a marked decrease in variability and falls to levels which are not different from females. Even though iron level in guano from both sexes exceeds nutritional need, male big brown bats appear to exhibit progressively greater dietary iron deficiency, and females may be iron deficient throughout the entire period of observance.

Fecal pellets collected from males were consistent in size and colour throughout the entire summer; however, among collections from females, atypical fecal pellets were found mixed with typical pellets during two specific time spans. Large, grey fecal pellets were found during the first 2 weeks of collection (while females were lactating), and small, black pellets were found mixed with typical pellets in the last three weeks of maternity roost occupancy. These pellets were analysed separately from typical guano and are reported in Table 3 . Compared to typical guano (Table 2), grey pellets are higher in nitrogen, sodium and potassium $(t=7.506, \mathrm{df}=34, P<0.001$; $t=6.033$, df $=34, P<0.001$; and, $t=12.91$, df $=34$, $P<0.001$, respectively) and lower in iron $(t=2.752$, $\mathrm{df}=34, P<0.01)$. These differences in size, colour and composition of grey guano strongly suggest that females from this roost fed heavily and opportunistically on atypical abundant prey during the last few weeks of lactation. Composition of the grey pellets suggest that, compared to typical prey, the insects eaten were not generally more nutritious, i.e. did not provide the deficient minerals iron and calcium. Compared to typical guano (Table 2), black pellets are significantly higher in potassium, calcium, magnesium, and iron $(t=2.563, \mathrm{df}=23, P<0.02$, $t=5.591, \quad$ df $=23, \quad P<0.001, \quad t=5.290, \quad$ df $=23$, $P<0.001$, and, $t=18.33$, df $=23, P<0.001$, respectively) and lower in nitrogen $(t=3.250, \mathrm{df}=23$, $P<0.01)$. The observation that ingested insects which resulted in the black pellets provide very large inputs of calcium (Fig. 1) and iron (Fig. 2), coupled with the lower available insect diversity in October, suggests that these female bats were feeding selectively on prey which fulfilled their specific nutrient deficiencies.

In summary, analyses of element level in guano of male and female big brown bats throughout the summer roosting period yield several nutritional implications. Guano from males is high and variable in sodium level throughout the summer, while all other measured elements (nitrogen, magnesium, potassium, calcium and iron) show progressive decreases, both in variability and concentration, as the summer progresses. Male E. fuscus may be in negative calcium and iron balances by the end of the summer roosting period. Fecal levels of all elements, except calcium, remain constant in guano from females throughout the period of observation (mid-lactation through the end of the summer roosting period). Calcium levels in guano from females are extremely low and nonvariable until the last few weeks before summer roost abandonment, and females appear to be in extreme negative calcium balance from mid-lactation until just before leaving the maternity roost. Iron levels in guano from females are also low and non-variable which implies inadequate dietary intake of that element. Guano from males was consistent in size and shape throughout the summer while atypical guano was collected from females during mid-lactation and just before roost exodus in the fall, therefore, the diet of females may be more diverse than the diet of males or may reflect variation in prey availability at different roost locations. Atypical guano (large, grey fecal pellets) from females in mid-lactation differs markedly in composition from typical guano collected at that time but does not contain high levels of calcium or iron and probably represents opportunistic feeding by females. Atypical guano (small, black fecal pellets) from the last few weeks of roost occupancy also differs in composition from typical guano collected at that time. The black pellets, however. contain very high levels of both iron and calcium, elements that are probably limiting nutrients, and may represent evidence of selective feeding.

Acknowledgements - We thank Mr and Mrs Kenneth Clark for allowing us unlimited access to their property and buildings and for their continuing interest in and support of our studies. Cooperation of the Grand Blanc Historical Society is gratefully acknowledged. Rob Downing aided in field aspects of these studies. We thank Drs Russell Schenck and Allen Kurta for useful and insightful comments on the manuscript. This study was partially supported by a Research Partnership Grant from The University of Michigan-Flint. 


\section{REFERENCES}

Bassett J. E. and Studier E. H. (1988) Methods for determining water balance in bats. In Ecological and Behavioral Methods for the Study of Bats (Edited by T. H. Kunz), Chap. 22, pp. 373-386, Smithsonian Inst. Press, Washington, D.C.

Kunz T. H. and Nagy K. A. (1988) Methods of energy budget analysis. In Ecological and Behavioral Methods for the Study of Bats (Edited by T. H. Kunz), Chap. 18, pp. 277-302, Smithsonian Inst. Press, Washington, D. C.

K wiecinski G. G., Krook L. and Wimsalt W. A. (1987a) Annual skeletal changes in the little brown bat, Myotis lucifugus lucifugus, with particular reference to pregnancy and lactation. Am. I. Anat. 178, $410-420$.

Kwiecinski G. G., Wimsatt W. A. and Krook L. (1987b) Morphology of thyroid c-cells and parathyroid glands in summer-active little brown bats, Myotis lucifugus lucifu$g u s$, with particular reference to pregnancy and lactation. Amer. J. Anat. 178, 421-427.
McNab B. K. (1982) Evolutionary alternatives in the physiological ecology of bats. In Ecology of Bats (Edited by T. H. Kunz), Chap. 4, pp. 151-200, Plenum Press, New York.

National Research Council (1978) Nutrient Requirements of Laboratory Animals. No 10., 3rd Revised Edition, National Academy of Sciences, Washington, D.C.

Ransome R. D. (1973) Factors affecting the timing of births of the greater horse-shoe bat (Rhinolophus ferrumequinum). Period. Biol. 75, 169-175.

Studier E. H., Szuch E. J., Tompkins T. M. and Cope V. W. (1988) Nutritional budgets in free flying birds: cedar waxwings (Bombycilla cedrorum) feeding on Washington hawthorn fruit (Crataegus phaenopyrum). Comp. Biochem. Physiol. 89A, 471-474.

Wilkinson L. (1987) SYSTAT: The System for Statistics, SYSTAT, Inc., Evanston, IL.

Wilkinson L. (1989) SYGRAPH, SYSTAT, Inc., Evanston, IL. 